\title{
Masculinidades virreinales: ser varón en los textos jurídicos de Juan de Matienzo y Francisco de Toledo (Virreinato del Perú, 1569-1581)
}

Viceroyal Masculinities: Being a Man in Juan de Matienzo and Francisco de Toledo's Legal Texts (Viceroyalty of Peru, 1569-1581)

Masculinités vice-royales: être un homme dans les textes légaux de Juan de Matienzo et de Francisco de Toledo (vice-royaume du Pérou, 1569-1581)

\section{Alvaro Ojalvo Pressac}

\section{OpenEdition}

Journals

Edición electrónica

URL: http://journals.openedition.org/rhj/3456

DOI: $10.4000 /$ rhj.3456

ISSN: 0719-4153

Editor

ACTO Editores Ltda

\section{Referencia electrónica}

Alvaro Ojalvo Pressac, « Masculinidades virreinales: ser varón en los textos jurídicos de Juan de

Matienzo y Francisco de Toledo (Virreinato del Perú, 1569-1581) », Revista Historia y Justicia [En línea], 11 | 2018, Publicado el 01 octubre 2018, consultado el 27 julio 2020. URL : http:// journals.openedition.org/rhj/3456 ; DOI : https://doi.org/10.4000/rhj.3456

Este documento fue generado automáticamente el 27 julio 2020.

Revista Historia y Justicia 


\title{
Masculinidades virreinales: ser varón en los textos jurídicos de Juan de Matienzo y Francisco de Toledo (Virreinato del Perú, 1569-1581)
}

Viceroyal Masculinities: Being a Man in Juan de Matienzo and Francisco de

Toledo's Legal Texts (Viceroyalty of Peru, 1569-1581)

Masculinités vice-royales: être un homme dans les textes légaux de Juan de

Matienzo et de Francisco de Toledo (vice-royaume du Pérou, 1569-1581)

Alvaro Ojalvo Pressac

\section{NOTA DEL EDITOR}

Recibido: 08 de julio de 2018 / Aceptado: 30 de septiembre de 2018

\begin{abstract}
“En Perú, el virrey Francisco de Toledo reunió a un círculo de juristas y de teólogos que aceptaron la tesis de Sepúlveda y convinieron en que, antes de que el indígena pudiese ser un auténtico cristiano, había que enseñarle cómo ser hombre"
\end{abstract}

\section{Palabras iniciales}

Repasando Las palabras que hemos seleccionado del historiador inglés David A. Brading, resultan sugerentes para discutir, de manera diferente, un momento y lugar específico dentro del pasado colonial americano. En este sentido, la expresión "enseñarle cómo ser hombre", se refiere a la "condición humana" de los indígenas. Este 
tipo de condición estaba relacionada con la idea de "humanus", es decir, educado, civilizado y, a su vez, ligado con "urbanus", cuyo término se vinculaba con toda persona que vive en las ciudades ${ }^{2}$. Aunque se pueda apreciar que, durante el periodo colonial americano, el significado de "ser hombre" se discutió desde una mirada ontológica, también es posible considerar dicho significado desde una propuesta teórica diferente: los estudios de masculinidad. Esta propuesta, basa sus objetivos en una pregunta central, a saber, cómo los varones -que piensan y actúan de diversas maneras sus identidades masculinas a lo largo de la historia- han afectado a otros varones en un espacio donde conviven y se desenvuelven entre sí, colocando en discusión la idea del poder.

2 La historia del género en América colonial, y su relación con el imperio español, no puede entenderse sin considerar las diferentes dinámicas de poder que articularon a los grupos sociales, las cuales no sólo reprodujeron sino que acentuaron sus diferencias de raza, sexo y género. El sociólogo peruano Aníbal Quijano utiliza el concepto "colonialidad del poder", para referirse a las diferentes formas en que la Corona castellana estableció: la (re)clasificación de las personas, la creación de instituciones que articularon dichas clasificaciones (la Corona española, la iglesia, etc.), la definición de espacios y la perspectiva epistemológica para articular una matriz de poder ${ }^{3}$. Por supuesto, el control y definición de las masculinidades y feminidades no estuvieron ajenos a dichas dinámicas de poder. Como ha explicado la filósofa argentina María Lugones, la colonialidad tiene una doble definición, como término "categorial", en tanto interactúa y se relaciona con otras categorías y como "fenómeno abarcador", en tanto ha permeado múltiples dimensiones de la sociedad. Ambas definiciones han construido una dinámica dicotómica (superioridad/inferioridad) en relación a la categoría sexo/género4.

3 Dentro de los diferentes contextos coloniales, esta dicotomía no sólo construyó una relación jerárquica entre varones y mujeres, también se dieron dinámicas complejas entre los diferentes varones ¿Cómo era ser un varón español criado en la península en comparación con el nacido en las "Indias"? ¿Cuáles eran los códigos culturales que la sociedad colonial americana demandaba para definir a un varón mestizo? ¿Qué significaba ser un varón indígena bajo la dominación hispana? Estas preguntas contienen una problemática en común, reflexionar sobre la masculinidad como una categoría histórica-cultural cuya construcción depende de múltiples factores tales como: las transformaciones que ha tenido un varón de manera individual, la diferencia entre varones según su posición social, las diferentes masculinidades que se generan entre los distintos grupos étnicos y las variaciones de los significados de "varón" y "masculinidad" a lo largo del tiempo5.

4 Las discusiones historiográficas sobre los estudios de género en las sociedades coloniales americanas fueron desarrolladas, en una etapa inicial -entre finales de los años de 1970 y mediados de la década noventa- a partir de los trabajos pioneros de Irene Silverblatt, María Rostworowski, Asunción Lavrin y María Emma Mannarelli ${ }^{6}$ cuyos objetivos, inspirados por los estudios de las mujeres, consistían en analizar cómo las indígenas, mestizas, negras y españolas, afectadas por las dinámicas coloniales, actuaron, en este escenario, como sujetos que tuvieron un impacto y relevancia en la historia ${ }^{7}$.

5 Estos primeros trabajos abrieron una puerta teórica-metodológica para dirigir la mirada hacia la influencia que tuvieron los varones no sólo en su relación con las 
mujeres, sino también entre ellos. Fue así como surgieron los estudios de masculinidad, cuyo objetivo sigue siendo deconstruir y complejizar la identidad masculina con el fin de comprender las múltiples formas de ser varón, así como la constante reelaboración de lo masculino tanto a través de la historia como en diferentes espacios geográficos ${ }^{8}$.

6 En contextos coloniales americanos, se destacan los trabajos de los historiadores Richard Trexler y Pete Sigal quienes centraron sus análisis en textos coloniales mesoamericanos, mientras que Michael J. Horswell se enfocó en los Andes ${ }^{9}$. El objetivo de estos tres autores fue comprender cómo los cronistas entendían las formas de ser varón en América durante los siglos XVI y XVII. Sergio Rivera-Ayala y Rubén Medina dirigieron su mirada hacia los textos fundacionales americanos, como el diario de Cristóbal Colón y las cartas de Hernán Cortés, donde se puede apreciar las primeras nociones escritas sobre las masculinidades indígenas e hispanas. Finalmente Ann Twinam, realizó una revisión sistemática de documentos procedentes de diferentes archivos de América Latina para analizar las dinámicas que ocurrían al interior de la élite hispanoamericana colonial vinculadas a la raza, las relaciones interpersonales, el honor femenino, etc., y cómo afectaron dichas dinámicas en la posición social del varón $y$ las diferentes formas en que se configuraron las identidades masculinas ${ }^{10}$.

7 Tanto los estudios de género como los estudios de masculinidad -centrados en el mundo colonial- han tenido como común denominador el análisis de los discursos escritos generados por las instituciones españolas y a partir de diferentes agentes letrados, tales como los cronistas, oficiales reales y juristas, tanto seculares como eclesiásticos. Estos discursos operaron de acuerdo a una serie de lógicas relacionadas con su "formación textual" (literarios, históricos, legales, etc.) y "tipo textual" (crónicas, relaciones, cartas etc.) ${ }^{11}$. Dichos textos también fueron símbolos e instrumentos para legitimar el poder español e imponer una determinada masculinidad, una masculinidad escrita. Aunque a primera vista, puede parecer obvio, la asociación "masculinidad escrita" y "soporte escrito" supone comprender que la construcción de las masculinidades dependerá del tipo de "soporte de comunicación" que encierra lógicas específicas de enunciación ${ }^{12}$. En este sentido, son sugerentes las palabras del historiador norteamericano Pete Sigal, cuando señaló que el investigador debe prestar atención a las sexualidades que, en contextos coloniales, se insertaron en soportes occidentales y se plasmaron de forma escrita ${ }^{13}$, lo que Federico Garza Carvajal ya había denominado como "fabricación textual" ${ }^{14}$. La nota de cautela puesta por Pete Sigal procedió de una serie de reflexiones que el autor realizó en torno al momento que los españoles arribaron a Mesoamérica y el modo en que estos entendieron las sexualidades desde una óptica hispano-católica ajena a las formas de pensar indígena.

8 Analizar las masculinidades escritas significa no considerarlas como "enunciados transparentes" ${ }^{15}$, sino más bien enunciaciones que surgieron de soportes europeos (el texto escrito mismo) cuyos autores (varones) formaron parte de una tradición histórica masculina específica. Se entenderá que la escritura misma de dichas enunciaciones dependerá del tipo y formación textuales, permeados por los códigos de género masculino del autor.

9 Estas reflexiones nos llevaron a plantear la hipótesis de que en el caso del Virreinato del Perú y, particularmente, durante el gobierno de Francisco de Toledo (1568-1581), tanto el mismo virrey como el letrado Juan de Matienzo, mantuvieron una preocupación no sólo por describir los comportamientos sexuales que tenían los españoles e indígenas, sino que a través de dichos enunciados también discutieron las 
maneras en que los varones debían actuar (sus performances de género) de acuerdo a las normas hispano-católicas. Es importante precisar que si bien existieron diversas masculinidades y jerarquías al interior de los grupos españoles como entre los indígenas, además de masculinidades mestizas, esclavas negras, mulatas, etc., que interactuaron en diferentes espacios, nuestro propósito es analizar las construcciones discursivas, elaboradas por los dos letrados mencionados, cuya orientación fue generar dos modelos masculinos, el español y el indígena. Esta dicotomía dominante/dominado fue parte de la estrategia de la Corona castellana para ordenar ambas categorías sociales e imponer y legitimar una determinada manera de ser varón y, a partir de allí, perpetuar la dominación masculina sobre los indígenas de manera natural, es decir, dóxicamente ${ }^{16}$. Dicha estrategia tuvo un doble efecto, por un lado, una dicotomía jurídica sobre la naturaleza misma de los indígenas y, por otro, una división de ambas categorías con un contenido de género. Aun cuando la obligatoriedad de pagar tributo fue central para la elaboración de la categoría jurídica de indio, no deben subestimarse otros elementos como la religión e, incluso, el género como sustento de esa dominación ${ }^{17}$.

10 Aunque la importancia de las identidades de género a partir de las construcciones discursivas en los Andes coloniales ya ha sido explorada por Michael Horswell ${ }^{18}$, nuestro objetivo es relevar la importancia del discurso legal y sus efectos sobre la construcción de las masculinidades. Para discutir dicha problemática, centraremos nuestro trabajo en dos obras jurídicas de conocida impronta en la historia del virreinato: las "ordenanzas" (1575-1580) del virrey Francisco de Toledo y la obra "Gobierno del Perú" (1567) del jurista Juan de Matienzo. La elección de ambos textos se debe a que seguimos el planteamiento de José Rabasa, según el cual destaca la importancia de abordar los textos de manera individual debido a que "abre la posibilidad de comprender la específica interacción de escritores y textos con la formación discursiva que define quién tiene autoridad para hablar y qué es un 'conocimiento legítimo' "19.

11 ¿Por qué abordar ambos textos legales desde los estudios de masculinidad? Recordemos que los varones al ser "sujetos modelados por el género" ${ }^{20}$ registrarán su realidad de acuerdo a las formas históricos-culturales específicas en que fueron formados como tales. Analizar las “ordenanzas" y el "Gobierno del Perú", desde esta corriente teórica, implica considerar que la información contenida en ambas obras no fue escrita por cualquier varón. Por un lado, se trata del jurista Juan de Matienzo quien se destacó como relator de la Chancillería en Valladolid para luego ser designado como oidor de la Audiencia de Charcas en 1558, cargo que asumiría al momento de su llegada a Lima en 1561 y en el que permanecería hasta su muerte en 1579, convirtiéndose en el oidor más antiguo. Además, obtuvo el cargo de corregidor y justicia mayor de la Villa Imperial de Potosí (1577), puesto en el que fue designado por el virrey Toledo ${ }^{21}$. Por otro, nos referimos a Francisco de Toledo, caballero de la Orden de Alcántara quien asumió el cargo de Virrey del Perú en 1569. Durante su gobierno organizó el territorio andino a través de las reducciones, generalizó el tributo en metálico, regularizando el trabajo indígena a través de la mita y reemplazando los etnónimos que los aglutinaban en torno a un señorío por la categoría de "indio" a través de la cual se intentaron borrar las diferencias entre grupos étnicos ${ }^{22}$. Esta organización territorial reforzó los derechos de la Corona en las "Indias". A su vez, apoyó la evangelización por medio del estudio del quechua y el aimara en la universidad, además de favorecer las doctrinas jesuitas ${ }^{23}$. 

con la realidad andina, plasmándose en las obras jurídicas analizadas. El "Gobierno del Perú" recoge la teoría política clásica española donde uno de sus argumentos era que "la autoridad política existía para asegurar el bien común", presentando al gobierno de los Incas como una tiranía, por lo que justifica el derecho de los españoles sobre el territorio andino ${ }^{24}$. Las "ordenanzas" del virrey, por su parte, contemplaron diferentes elementos para la "buena gobernabilidad" de todo el virreinato. En su obra se trataron temáticas como el consumo de la coca, la reglamentación de la minería, y aspectos puntuales sobre el comportamiento de los indígenas tanto en las ciudades españolas como en los pueblos de indios a fin de vivir conforme a las leyes hispanas ${ }^{25}$. experiencia en la realidad andina, gracias a los cargos administrativos que obtuvieron y su identidad de género, nos ofrecen las pautas para considerar que la historia jurídica colonial también debe analizarse desde la perspectiva de los estudios de masculinidad. Cómo no relevar la importancia de esta perspectiva si los funcionarios de la Corona, que crearon normas para los habitantes del virreinato, también fueron varones "moldeados por el género". Planteamiento que Walter Mignolo ha expresado en su reflexión en torno a la modernidad/colonialidad, donde destaca que el derecho colonial "no está establecido por el derecho natural o divino, sino por los intereses humanos y, en este caso, los intereses de los castellanos cristianos de sexo masculino" 26 .

Desde un punto de vista metodológico y siguiendo a los investigadores citados, nos aproximaremos a los estudios de las masculinidades desde el constructivismo social, tomando ambos textos jurídicos como fuentes primarias para el análisis. A partir de esta opción metodológica y recuperando enfoques interdisciplinarios identificaremos los enunciados que trataron de manera directa e indirecta las descripciones sobre los varones.

de la etnohistoria que considera a los autores de este periodo -como los cronistas y los letrados- como etnógrafos. Esta perspectiva permite interrogarnos sobre cómo las clasificaciones en torno a los indígenas pasaron por un filtro moral y religioso, construyendo a los sujetos enunciados desde la mirada del autor ${ }^{27}$. Tanto los estudios de masculinidad como la etnohistoria, recogen la propuesta de Michel Foucault respecto a la idea de control y vigilancia a través del dispositivo panóptico. Dicha idea no sólo resulta válida para considerar las formas de control dentro del sistema penitenciario francés durante el siglo $\mathrm{XIX}^{28}$, sino también para analizar las sociedades coloniales americanas, especialmente, durante el proceso de implantación de las "reducciones" cuando las poblaciones indígenas fueron reasentadas y concentradas compulsivamente en un espacio delimitado, obligándolas a abandonar el patrón andino de asentamiento disperso ${ }^{29}$.

icación del panóptico en las sociedades coloniales americanas también puede discutirse desde un plano discursivo y, en el caso específico de esta investigación, desde los textos jurídicos. Las descripciones realizadas por Toledo y Matienzo contienen enunciados donde se destacaron las ideas de control y vigilancia orientadas a disciplinar formas indígenas de masculinidad contrarias a las normas legales. En dichos enunciados se pueden detectar las definiciones sobre lo que significaba ser varón y los diferentes tipos de masculinidades que construyeron discursivamente ambos letrados. 


\section{Los escritos jurídicos de Matienzo y Toledo en la historia del Virreinato del Perú}

17 La producción de textos desarrollados durante el gobierno de Francisco de Toledo y la misma presencia del virrey se deben a una serie de sucesos que conllevaron a la reorganización y reforma en los Andes coloniales ${ }^{30}$. Juan Carlos Estenssoro, al referirse al virrey, señala que "las circunstancias políticas cambiaron definitivamente (...) el proyecto colonial y sus instituciones fueron definidos y permanecerán sin cambios significativos hasta el cambio dinástico y, más precisamente, hasta el reinado de Carlos III" ${ }^{\prime 1}$.

18 Siguiendo al historiador italiano Manfredi Merluzzi ${ }^{32}$, el periodo colonial temprano en el Perú puede dividirse en tres ciclos: Las primeras décadas del siglo XVI, corresponden al ciclo denominado "conquista", en el cual, aun cuando se generaron alianzas entre la elite cuzqueña y los conquistadores, no hubo un interés por comprender con "profundidad el mundo andino". Durante esta etapa, como producto de la serie de conflictos generados por los encomenderos para acrecentar su poder, así como de la pugna entre los almagristas y pizarristas, la Corona vio la necesidad de controlar y ordenar el territorio mediante la creación del Virreinato en 1542. En un segundo momento, que comenzó a mediados de dicho siglo y que el autor ha denominado "pacificación", se puso en cuestión la idea de seguir utilizando las estructuras andinas, en beneficio de la Corona y se propuso desarrollar una reforma político-social ${ }^{33}$. El último ciclo, al que Manfredi denomina "reestructuración", se caracterizó por una serie de modificaciones administrativas (hacienda pública, corregidores de indios, etc.) que tuvieron lugar durante el gobierno de Lope García de Castro (1564-1569).

Debemos agregar que la falta de "profundidad" en el conocimiento del mundo andino tuvo un vuelco a partir de las discusiones conciliares que tuvieron lugar en la ciudad de Lima desde mediados del siglo XVI, la publicación del "Lexicón o Vocabulario de la lengua general del Perú" (1560) del dominico Domingo de Santo Tomas y la obra monumental de Bartolomé de Las Casas, "Apologética Historia Sumaria" (1559) ${ }^{34}$. Con respecto a las discusiones conciliares, éstas tuvieron lugar entre 1551-1552 y 1567-1568 cuando se celebraron el Primer y Segundo Concilio Limense, respectivamente. Ambos fueron organizados por el primer arzobispo de Lima Fray Jerónimo de Loayza. Los objetivos de los concilios fueron adoctrinar a la población andina por medio de los sacramentos (bautismo, penitencia y matrimonio) y regular las conductas del clero y de los españoles. Para cumplir dicho adoctrinamiento, los sacerdotes debían conocer cabalmente las costumbres de los indígenas con la finalidad de identificar los elementos que los definían como no cristianos. Para la conversión de las comunidades andinas, se llevó acabo la tarea de que los sacerdotes conocieran las lenguas indígenas, especialmente, quechua y aimara. Los textos publicados por los concilios entregaron una rica información sobre la comprensión de las prácticas andinas coloniales ${ }^{35}$. Con respecto a Fray Domingo de Santo Tomás, tuvo una participación activa en el proceso de evangelización entre los indígenas de la sierra y la costa peruana, además de convertirse en obispo de Charcas. Gracias al constante contacto que tuvo con las comunidades andinas, se destacó en sus habilidades lingüísticas, siendo consultado por el cronista y autor de la obra "Crónica del Perú" (1553), Pedro de Cieza de León y por el padre Bartolomé de Las Casas ${ }^{36}$. Al igual que Santo Tomás, Las Casas ingresó a la orden de los dominicos en 1522 donde posteriormente recorrería Mesoamérica y el Caribe en 
favor de los derechos indígenas y oponiéndose a la encomienda. Su defensa de los indígenas y la denuncia de la explotación que ejercían los encomenderos, se traduciría en la promulgación de las Leyes Nuevas (1542) y el debate, sobre la naturaleza y sujeción de los indígenas, con el teólogo Juan Ginés Sepúlveda en Valladolid (1550) ${ }^{37}$.

Estos tres ciclos constituyeron la antesala de lo que sería la maduración del sistema político que encabezó el virrey Francisco de Toledo quien nutrió su administración de un círculo de prestigiosos letrados. Un primer grupo de "colaboradores" estuvo integrado por quienes intervinieron en el escenario religioso como Fray García de Toledo y el jesuita José de Acosta. Este último, fue uno de los teólogos más destacados que se abocó a discutir el problema de la condición de los indígenas. Acosta conoció directamente las culturas andinas al viajar por las regiones del Cuzco, Arequipa, La Paz, Potosí y Chuquisaca donde aprendió quechua y conoció al Virrey Toledo que por entonces estaba realizando su visita general por el virreinato. Este jesuita ha sido conocido por la creación de dos grandes obras, De procuranda indorum salute (1588) que fue un "tratado sobre la evangelización" y de "ética política" y su "Historia natural de la Indas" (1590), donde no solamente fue una crónica sino que destaca las causas del porqué los grupos indígenas eran gente "nueva y extraña"38.

El segundo grupo, se puede definir como el de los letrados laicos, representados por, Gonzales de Cuenca, el licenciado Polo de Ondegardo, Sánchez de Paredes, Juan de Matienzo $^{39}$ y Pedro Sarmiento de Gamboa. Dentro de este grupo queremos destacar a dos integrantes. En primer lugar, al licenciado Polo quien realizó una serie de trabajos que lo convirtieron en un gran conocedor del mundo andino. Fue jurista, conquistador y encomendero. Su conocimiento de los Andes se puede apreciar en escritos tales como Tratado y auerigación sobre los errores y supersticiones de los indios (1584) ${ }^{40}$. Por su parte, Pedro Sarmiento de Gamboa llegó al Perú en 1544 luego de una vida bastante agitada: perseguido por la Inquisición por falsificar en broma una sentencia, fue desterrado a España temporalmente y organizó una expedición por el Pacífico. Durante la administración de Toledo, Sarmiento de Gamboa presentó la segunda parte de su Historia índica donde narra la historia de los gobernantes incaicos desde Manco Cápac hasta Huáscar. Dicha obra ayudó a retratar a los incas como "usurpadores y tiranos" y así lograr su objetivo, legitimar la presencia española en los Andes ${ }^{41}$.

Los escritos de dichos colaboradores no solo estaban permeados por los eventos políticos, religiosos y económicos que tenían lugar en el Perú, sino que -desde un plano discursivo- también estaban inmersos en las discusiones acerca de la naturaleza de los indígenas, y que se pueden rastrear con fuerza, desde mediados del siglo XVI cuando "la producción de escritos experimentó un giro significativo" ${ }^{42}$.

Este giro no sólo tuvo que ver con un mayor interés de la corona para comprender la realidad andina a través de los trabajos como los de Pedro de Cieza de León o Juan de Betanzos, sino también con la discusión en torno a la realidad ontológica de los indígenas que dio lugar los debates teológicos y jurídicos entre Bartolomé de Las Casas y Juan Ginés de Sepúlveda en la Junta de Valladolid (1550-1551). Dicho debate se organizó en torno a un problema mayor, los "justos títulos", es decir, el derecho jurídico que tenían los Reyes de Castilla y León para el sometimiento de las comunidades indígenas. Este problema tuvo sus orígenes en las discusiones en torno a la naturaleza del indígena, especialmente, desde la "Escuela de Salamanca" en 1533, donde se destacó el rol que jugó el teólogo Francisco de Vitoria. Vitoria explicaba que aunque los indígenas (aztecas e incas) no eran irracionales y vivían en ciudades, debían 
vivir acorde a las costumbres que derivaban de la ley natural para convertirse en hombres virtuosos. Según los argumentos de Vitoria y basándose en las ideas aristotélicas, los indígenas carecían de estos elementos al ser considerados como niños, es decir, no poseían educación y se guiaban por sus pasiones. Esta premisa fue clave para fundamentar la idea de que los españoles debían gobernar a los indígenas para guiarlos y educarlos en las costumbres cristianas ${ }^{43}$. Los postulados de Vitoria fueron puestos nuevamente en consideración en el marco del debate entre Las Casas y Ginés de Sepúlveda.

Bartolomé de Las Casas era partidario de que la guerra contra los indígenas era injusta y argumentaba que por ley natural todo sujeto, incluyendo a los indígenas, era libre. Pero aun cuando la teoría lascasiana reconocía la autoridad papal sobre los no cristianos, consideraba que se trataba de una jurisdicción más voluntaria que coercitiva, por lo cual, el Sumo Pontífice no tenía potestad sobre los indígenas para forzarlos a creer, pero sí para enseñarles acerca de la falsedad de sus divinidades. En el caso de la autoridad real, siguiendo los postulados medievales, consideraba que los reyes eran designados por providencia divina para el bien común del pueblo, por lo que tenían responsabilidades que se traducirían en obligaciones temporales y espirituales hacia sus súbditos, incluyendo a los habitantes del Nuevo Mundo. Entre las obligaciones temporales, los soberanos no debían explotar a sus vasallos, mientras que las espirituales consistían en gobernarlos bajo las leyes cristianas. Pero el poder real no era ilimitado, el rey no podía imponer la sujeción o la esclavitud, sino que debía "usar su autoridad solamente para aumentar el bien espiritual y material de sus súbditos"44.

Una argumentación contraria fue presentada por Juan Ginés de Sepúlveda, conocido como el "Tito Livio español" quien estudió humanidades en Córdoba y se doctoró en Artes y Teología en el Colegio Español de Bolonia (1515-1523). Este humanista fue nombrado cronista y confesor real por los reyes Carlos I y Felipe II ${ }^{45}$. Sepúlveda clasificó a los americanos como homunculi (homúnculos), es decir, más cercanos a las bestias que a los hombres racionales ${ }^{46}$. En virtud de esa condición y siguiendo los postulados que el jurista Juan López Palacios Rubios estableció en la Junta de Burgos (1512), consideró a los indígenas como servi a natura, es decir, como seres que debían "servir a sus superiores y a sus amos naturales, los españoles" por derecho natural. Estos argumentos basados en postulados aristotélicos también sirvieron de bases para sustentar la teoría de la "guerra justa" contra los indígenas. La propuesta de considerar a los indígenas como servi a natura encerraba una reflexión profunda orientada a justificar la presencia hispana en el territorio americano. Dentro del discurso intelectual -siguiendo las ideas de Aristóteles y Santo Tomás- había cuatro tipos de bárbaros. Los primeros eran clasificados como bárbaros en un sentido amplio, es decir, todos los hombres inhumanos. Los segundos fueron las personas que carecían de letras (secundum quid) quienes, desde la visión europea, eran los que no conocían el latín. Los terceros eran definidos como bárbaros por las malas condiciones geográficas, convirtiéndolos en personas carentes de razón, crueles, estúpidos y, por lo tanto, faltos para poder gobernar. Finalmente, estaban los bárbaros que no conocen el cristianismo y su filosofía. Juan Ginés de Sepúlveda al ser partidario del tercer postulado, defendía la idea que los indígenas por su condición natural de siervos y su incapacidad de gobernarse a sí mismos, debían ser gobernados por la fuerza para convertirse en cristianos y súbditos de los reyes ${ }^{47}$. 

Sepúlveda. Aunque sus obras no fueron publicadas, su pensamiento se vio reflejado en los escritos que llevaron a cabo los colaboradores del virrey Toledo ${ }^{48}$. En estos textos se puede apreciar que el cristianismo operó como una "fuerza epistémica" que ha definido la naturaleza de los indígenas ${ }^{49}$; fuerza que puede sintetizarse en los tres puntos centrales que se elaboraron durante la administración del virrey. En primer lugar, la enunciación de los incas como tiranos. Esta idea se puede encontrar en los escritos de Juan de Matienzo, Pedro Sarmiento de Gamboa y Polo de Ondegardo que tuvieron una fuerte influencia en las obras de Toledo ${ }^{50}$; el segundo, la averiguación de las prácticas religiosas indígenas mayormente representada en la información recopilada por Polo de Ondegardo; y el tercero, la imposición político imperial de la corona castellana ${ }^{51}$.

"fuerza epistemica", que alimentó los escritos de los colaboradores de Toledo, puso en discusión un tema mayor que influyó en la construcción discursiva sobre los indígenas. Esta construcción -que fue elaborándose durante todo el siglo XVIdesarrolló una determinada forma de "escritura etnográfica" como ha sido analizado por David Solodkow. Por escritura etnográfica, este autor entiende a un "espacio discursivo" donde se construyen "categorías discursivas" que se originan a partir de una "episteme colonial" -eurocéntrica, católica e hispana- donde se exponen los "mecanismos discursivos" para clasificar a un "otro" desde la "autoridad" del etnógrafo ${ }^{52}$.

Esto no sólo permite comprender que durante el gobierno de Francisco de Toledo, se llevaron a cabo determinadas construcciones sobre los indígenas, bajo un "conjunto de reglas de formación discursiva", sino que también dichas construcciones operaron bajo la mirada masculina del "etnógrafo colonial", generando "tropos de sexualidad" 53 . Hemos tomado este concepto del trabajo de Michael Horswell, quien ha seguido la línea de Hayden White, para comprender cómo ciertos tropos, jugaron un papel importante en la transformación de las subjetividades desarrolladas por españoles, mestizos y escritores indígenas para interpretar la realidad sexual y de género en el mundo andino. Los tropos de sexualidad permiten discutir cómo las clasificaciones en torno a los varones generaron diferentes identidades masculinas. Además la propuesta de Horswell permite realizar la siguiente pregunta: ¿qué tipo de masculinidades se construyeron?

La importancia de analizar las masculinidades bajo esta perspectiva, está vinculada como lo ha propuesto Richard Collier- con la necesidad de reflexionar sobre las maneras en que la ley ha moldeado las configuraciones de género masculinas. Este autor, de influencia foucaultiana, sostiene que los mecanismos normativos que moldean la relación entre masculinidad y ley forman parte de un cuadro mayor en torno al poder, propios de una sociedad disciplinaria ${ }^{54}$. Este planteamiento invita a preguntarse ¿cómo se construyeron las masculinidades dentro de los procesos normativos generados en textos jurídicos como los de Francisco de Toledo y Juan de Matienzo?

\section{Normativizando las masculinidades coloniales}

Las normas establecidas en los Andes, como en la mayor parte de América, se construyeron a partir de la tradición jurídica castellana, la cual provenía de "esquemas jurídicos bajo medievales" 55 . Como hemos mencionado, dicha tradición no se puede comprender sin la presencia del cristianismo, presente en las leyes elaboradas durante 
la administración de Toledo. Kenneth J. Andrien ha destacado que "el cristianismo suministraba las normas éticas que regían la conducta de las personas en la sociedad más amplia" y las autoridades de la Corona debían velar por "promulgar leyes que encajaran dentro de un código legal moral global”56.

Efectivamente, desde la Corona castellana, había una preocupación por incorporar a los habitantes del "Nuevo Mundo" dentro de los códigos morales-legales católicos, las características de esta "escritura [etnográfica] es entonces la inscripción temporal y espacial del Otro bajo la disposición del ego y la "autoridad" del etnógrafo" ${ }^{57}$. La incorporación de los indígenas a las lógicas hispano-católicas conllevó a realizar un ejercicio etnográfico y plantearse sobre la misma ontología de un "otro", cuya discusión teológica-jurídica fue madurando durante todo el siglo XVI, con las Leyes de Burgos (1512), la ya mencionada Junta de Valladolid y, por supuesto, los concilios limenses.

La relevancia de estas discusiones residió en que no sólo colocaron los cimientos para comprender las clasificaciones ontológicas en torno a los indígenas, sino también para empezar a construirse definiciones sobre las mismas identidades de género ${ }^{58}$. En otras palabras, los etnónimos ${ }^{59}$, adjetivos clasificatorios sobre el otro, tales como "bárbaros" e "idolatras", formaron las bases para establecer una división entre cristianos/nocristianos y, a partir de esta línea divisoria, identificar cuáles eran las características que debían tener los sujetos para comportarse de acuerdo a su género. El primer término (bárbaro), ya explicado por Juan Ginés de Sepúlveda, seguía los planteamientos aristotélicos-tomistas de designar al indígena como una persona incivilizada, por lo tanto, como un otro (eterón) o extraño (xenón) ${ }^{60}$. El segundo (idólatra), estaba relacionado con la adoración de ídolos, asociándose inevitablemente a la práctica de cultos falsos ${ }^{61}$. A partir de los trabajos realizados por los extirpadores de idolatrías durante el siglo XVII, el historiador Kenneth Mills define a la idolatría como toda acción incivilizada, oscura y salvaje que realizaron las comunidades andinas ${ }^{62}$.

Al definir a los indígenas como bárbaros e idólatras fue inevitable que las clasificaciones sobre el género estuviesen inmersas bajo estos parámetros teológicosjurídicos. En este sentido, las leyes o normas, con una orientación moral, operaron también en torno a los individuos que no poseían un pensamiento, forma de vestirse o conducta apropiados al modelo de género hispano-católico.

En Europa, durante el siglo XVI, diferentes religiones definieron y controlaron las múltiples maneras en que se debía entender lo que significaba ser varón. Por ejemplo, el calvinismo explicaba la masculinidad a partir de la relación entre la familia, la ciudad y la iglesia. Para un calvinista, su deber como varón se expresaba en el objetivo de convertirse en un proveedor material y espiritual para su familia. Para el caso católico, un varón, bajo ningún punto de vista, debía comportarse como una mujer y cualquiera actitud afeminada se consideraba un insulto ${ }^{63}$.

La orientación moral de las normas aplicadas durante el gobierno de Francisco de Toledo siguió esta operación, prescribiendo lo que los varones debían hacer para que sus masculinidades estuvieran cercanas a lo que dictaban los esquemas morales católicos. La definición de "panóptico" de Michel Foucault -como un espacio de "vigilancia, control y corrección" -, tiene sentido al analizar los textos jurídicos elaborados por Toledo y Matienzo ${ }^{64}$. En ambos textos primaron aquellas ideas que sostenían que los indígenas debían vivir en "buena policía" que, según el diccionario de Sebastián de Covarrubias (1611) se definía como el "Consejo de policia, el que gouierna las cosas menudas de la ciudad" ${ }^{65}$. Al proponer, y más tarde establecer, que los 
indígenas se reunieran y vivieran en "pueblos", tanto Matienzo como Toledo materializaban la noción de panóptico, en la medida en que las reducciones de indios actuaron, entre otras cosas, como un dispositivo de control ${ }^{66}$. Pero, tal como ha señalado Foucault, la palabra "policía”, en contextos coloniales, implicó además la idea de "intervención" ${ }^{67}$, cuyo objetivo era establecer un cierto tipo de ordenamiento político pero también moral. En ese sentido, Juan de Matienzo señalaba que:

"Entre otras cosas a que tiene obligación Su Magestad y los encomenderos de indios en su nombre, una es enseñarles la policía humana, para que enseñados en nuestra Santa fe católica que es el principal intento que todos debemos tener"68. comprender que dicha palabra tiene una serie de significados ligados al orden, que también incluye al género. En este caso, el "orden de género" se organiza de acuerdo a lo que el grupo social que detenta el poder ya sea político, socioeconómico o simbólico considera correcto o incorrecto, legítimo o ilegítimo para ser considerado varón o mujer. historiadora Mery Weisner-Hanks establecieron cuando revelaron que las ideologías sexuales, durante la Edad Moderna, estaban organizadas según las lógicas de la religión cristiana $^{69}$. Por lo tanto, las masculinidades y feminidades estarían ligadas a lo que la Iglesia consideraba indicadores decisivos para convertirse en un "verdadero" varón o mujer, es decir, pensar, actuar y vestirse de acuerdo a lo que dictaba la religión católica. Una lectura más aguda, de las palabras enunciadas por Matienzo, muestra quiénes eran los sujetos que debían velar por dicho ordenamiento: el Rey y los encomenderos. El jurista destacaba que la autoridad debía ser ejercida por varones aunque no por cualquier varón. Al respecto, Matienzo señalaba que el poder sólo podía ser ejercido, siguiendo a Platón, por "personas nobles y dignos varones y muy valerosos"70. de las normas debía ejecutarse por aquellos que poseían una determinada masculinidad: nobles, dignos y valerosos. Las características que entrañaba cada uno de estos términos se pueden encontrar en el diccionario de Sebastián de Covarrubias. El primero de ellos, remitía a alguien "hidalgo y bien nacido". José Luis Martínez nos recuerda que la palabra "verdadera" provenía de la "boca de los nobles"71. El segundo término refería a tener "honra", es decir, era aquel que poseía "reuerencia, cortesía q[ue] se haze a la virtud"72. Para Matienzo, los que debían controlar y vigilar a los grupos sociales que conformaban la sociedad virreinal eran los varones que estaban en la cúspide de la jerarquía social, cuya "hombría" -término relacionado con la moralidad ${ }^{73}$ - debían ser el modelo que debían seguir los otros varones.

atienzo, además, invitaba a reflexionar sobre la construcción de una jerarquía masculina inspirada en un orden de género, hispano-católico. Esta jerarquía situaba a los varones españoles de la elite en la cúspide social y les otorgaba la potestad de ejercer una "masculinidad hegemónica" 74 . Esta categoría puede definirse como el grupo de varones que ejercen diferentes poderes sobre otros varones, regulando cómo estos deben manifestar sus identidades masculinas en virtud, de las normas producidas y ejercidas por el grupo dominante.

40 Esta preocupación también se hizo presente en la pluma de Francisco de Toledo. Al igual que Matienzo el virrey consideró que los varones españoles debían ser los ejemplos a seguir. Pero, en este caso, Toledo enuncia, de manera explícita, que el grupo 
hegemónico debía operar de forma relacional, ejerciendo la masculinidad hispana, como el único modelo para los indígenas: "Primeramente se os encarga mucho que viváis como cristiano, dando buen ejemplo a los dichos indios como de vuestra cristiandad y celo que habéis tenido y tenéis de mirar por los indios"75. Hay una intencionalidad clara en que los indígenas no sólo debían ser controlados por autoridades cristianas, sino que, a su vez, las mismas comunidades andinas debían ser educadas por ellas ${ }^{76}$ :

"Y porque la principal causa de la visita general es para dar orden y forma cómo los indios tengan competente doctrina y mejor puedan ser industriados en las cosas de nuestra santa fé católica y con más facilidad y comodidad se le puede administrar los sacramentos y sean mantenidos en justicia y vivan políticamente como personas de razón y como los demás vasallos de su Majestad"7?.

41 Tanto Matienzo como Toledo recogen la tradición hispano-católica de presentar a las autoridades como los únicos modelos masculinos a seguir. Esta tradición, que se remontaba al medioevo, estaba influenciada por la teoría aristotélica de la superioridad moral del varón sobre la mujer, los tratados, como el del filósofo Filón de Alejandría, que exaltaban la naturaleza racional de los varones o los tratados médicos que describían la fortaleza y la perfección de la complexión masculina respecto de la femenina $^{78}$.

Enunciar a dichas autoridades como representantes de la masculinidad hegemónica, generó un efecto en la construcción discursiva y en la dirección de las normas que estaban relacionadas con las materias de género. Toledo ya explicaba que los que vivían en la "república de indios" debían "ser enseñados e industriados en las cosas de nuestra santa fe católica, ley natural y buena policía y que cesen sus vicios y borracheras" 79 . Si bien, Covarrubias no definió el término "vicio", podemos destacar que, durante el periodo temprano-colonial, ya existía una tradición, a partir de los diferentes letrados en asociar esta palabra con lo moral-sexual. Esto permite vislumbrar que las actividades relacionadas a dichos vicios podían colocar en peligro el modelo masculino español que había comenzado a instalarse durante los primeros años del siglo XVI ${ }^{80}$. ¿Qué tipo de vicios llamaron la atención del virrey y del jurista que exigían ser normados? Uno de los vicios que siempre ha estado presente en las discusiones teológicas fueron las formas en cómo las comunidades andinas comprendían el matrimonio. Ya en el Primer Concilio Limense se puede observar una preocupación por este tema. La Constitución 17 establecía que, "si algunos se hallaren casados verdaderamente, según sus ritos y costumbre, con sus propias hermanas, permitimos que se retifique [sic] el matrimonio en la haz de la Iglesia" ${ }^{11}$. Por supuesto, este tema era de largo aliento, cuyos prolegómenos surgieron de las reflexiones propuestas por San Pablo quien conformó las bases teológicas y del Derecho clásico sobre el matrimonio como símbolo de la unión en espíritu y en carne que mantiene Cristo con su esposa ${ }^{82}$. Con respecto a este tema el virrey Toledo menciona:

"hay costumbre entre los indios casi generalmente de no casarse sin primero haberse conocido y tratado y conversado algún tiempo y hecho vida maridable entre sí como si verdaderamente lo fuesen, y les parece que si el marido no conoce primero a la mujer y por el contrario, que después de casados no pueden tener paz y amistad entre sí, lo cual hacen ofensa de Dios Nuestro Señor por persuasión diabólica, y conviene proveer en ello de remedio, ordeno y mando que se procure así por los sacerdotes, corregidores, cacique y alcaldes persuadir y quitar a los dichos indios esta costumbre tan nociva y perniciosa a su conversión, policía y 
cristiandad, haciendo castigos ejemplares en los dichos indios que lo contrario hiciesen" $"$. católicos del matrimonio? El varón indígena era el que debía cumplir con dichas normativas generadas a partir de los modelos conyugales articulados en España ${ }^{84}$. En el pasaje recién expuesto, Toledo dirigió su atención hacia "el marido" como la figura que debía representar la mayor autoridad, dentro del matrimonio, recordando lo que el humanista valenciano Juan Luis Vives ya había mencionado a mediados del siglo XVI en su obra Instrucción de la mujer christiana (1524), "porque (según el Apóstol) [San Pablo] la cabeza de la muger es el varón, y la del varón es Jesuchristo" ${ }^{85}$. Esta idea rompió con las maneras de pensar que existían en el mundo andino sobre el matrimonio, donde las jerarquizaciones entre los varones y las mujeres eran muy diferentes a cómo se percibía en Occidente. En los Andes siempre estuvo presente la idea de la dualidad complementaria que, en este caso, correspondía a la idea de que la masculinidad no se entendía sin la feminidad y viceversa ${ }^{86}$.

varón indígena, para demostrar que había abandonado sus costumbres "nocivas y perniciosas" debía entrar al matrimonio para transformarse en un varón cristiano, es decir, un varón que utilizaba el matrimonio como "vehículo para la reproducción" y no como un placer meramente carnal ${ }^{87}$. Esta idea ya había sido expuesta por Matienzo al señalar que "Son enemigos del trabaxo y amigos de ociosidad si por fuerza no se les hace trabaxar son amigos de beber y emborracharse y idolatras, y borrachos cometen graves delitos. Comunmente son viciosos de mugeres" $\$$.

La enunciación de los indígenas como idólatras permitió que, tanto Matienzo como el virrey, utilizaran este término como una categoría que abrió las puertas para generar asociaciones del varón andino como un sujeto que ya no sólo tenía la potencialidad de romper las normas del matrimonio, sino de cometer otros pecados que producirían una fricción con las leyes generadas por el poder para instalar el modelo masculino hispano ${ }^{89}$. Como ha señalado Anthony Pagden, el verdadero idólatra sería el más "depravado"

Francisco de Toledo, permitió incorporar otro término al campo semántico de los etnónimos ya descritos -bárbaros, viciosos, entre otros- como fue el caso de la sodomía. En relación con este término, veremos que fue Juan de Matienzo quien le dedicó mayor atención. Dentro de los colaboradores en la administración de Toledo, Pedro Sarmiento de Gamboa también enunció dicha palabra ${ }^{91}$.

¿Qué se entendía por sodomía durante el periodo colonial? La sodomía dentro del "ranking de pecados" tales como, la fornicación simple, el estupro, el adulterio y el incesto, entre otros, fue considerado el peor" ${ }^{92}$. Dentro de la tradición escolástica tomista, se le otorgaba el primer lugar por el accionar performativo que implicaba. En otras palabras, como expone el artículo de Fernanda Molina en este dossier, el punto central de dicho pecado consistía en la "emisión seminal" por el "vaso indebido" decir, a través del ano, quebrantado, de este modo, el objetivo primordial del coito, la procreación. La atención de los letrados -como teólogos, juristas y médicos- sobre este pecado, se debió a la red de categorías que en sí misma contenía y que fue tremendamente complejo de discutir durante la Edad Media y Moderna en contextos coloniales. La sodomía, era considerada un pecado de lujuria (luxuria). Mark Jordan, ha explicado que la tipología de este pecado, tenía sus bases en las formulaciones de 
Alberto Magno para quien la sodomía era un pecado carnal y que no estaba contemplada en la ley humana, por su triple contenido: contra la gracia divina, contra la razón y contra la naturaleza ${ }^{94}$. Tomás de Aquino recogió las reflexiones de Alberto Magno y destacó el punto sobre la lujuria, como acto contra natura, colocando énfasis en el coito entre varones (concubitus masculorum) ${ }^{95}$. La razón por la cual era considerado un acto contra la naturaleza, se debía a que atentaba contra la idea de reproducción a través del desperdicio de la esperma ${ }^{96}$. ¿Por qué llamó la atención de un jurista como Matienzo?

Los trabajos de Fernanda Molina muestran, entre otros elementos, que el pecado y el delito estaban unidos (pecatum et delictum). Desde una perspectiva jurídica, había una "progresiva fusión entre los derechos canónico y romano" que conllevó a la “ criminalización del pecado y de pecaminosidad del delito" ${ }^{97}$. Se puede apreciar esta fusión entre pecado y delito al revisar las palabras de Matienzo:

"si algún pleito hobiera entre los mesmos indios, procure de los concertar, y si no puediere, determínelo breve y sumariamente, sin tela de juicio; y si fuese creminal, remítalo a la justicia más cercana y invíe al delincuente preso, para que se haga de él justicia; no usando de tanto rigor como si fuera hombre de muncho entendimiento, antes usando de toda equidad; atento su imbecilidad y baxo entendimiento, si no fuere delito grave de muerte, alevosía o pecado de sodomía" ${ }^{98}$.

Pectatum et delictum no sólo quedan unidos al ser considerados inescindibles, también cuando el jurista (re)afirma esta idea al clasificar a los indígenas con el etnónimo "baxo entendimiento". No es menor mencionar que Covarrubias definió "entendimiento" como "Entendimiento a la ley" ". Jurídicamente hablando, hay una relación entre la falta de entendimiento de la ley y su relación con la práctica del pecado de sodomía. Recordemos que la sodomía, al ser una especie de los pecados de lujuria, se asociaba a una persona carente de razón. German Morong señala que puede apreciarse las primeras representaciones sobre la sodomía en América con Juan de Quevedo, obispo del Darien (1519), al relacionar a los indígenas como, "seres irracionales movidos única y exclusivamente por pasiones aberrantes"100.

50 Esta idea también fue expuesta por Juan Ginés de Sepúlveda, al asociar el "pecado abominable" con los indígenas para justificar, entre otros factores, la guerra contra ellos $^{101}$. Es importante subrayar que el término "abominable" se entendía como una "cosa aborrecible y fea, insufrible y detestable"102. Se puede apreciar que los debates teológicos y jurídicos abrieron el campo semántico para formar una red de significados en torno a la sodomía, como fueron la lujuria y la falta de entendimiento. En esta apertura semántica, también se asoció la sodomía como un "pecado abominable":

"mi intención es tratar solamente del reino del Perú, dejaré de decir algunas causas que los teólogos y juristas de nuestro tiempo largamente tratan y examinan para fundar que las Indias fueron justamente ganadas, como son porque el sumo Pontífice concedió al rey de España estas tierras y le hizo príncipe de ellas; porque el Emperador Don Carlos nuestro señor de gloriosa memoria era señor de todo el mundo por razón del Imperio, y en su tiempo se purgó el vicio (si alguno hubo antes en lo adquirir); porque estos reinos se hallaron desiertos por los españoles; y porque los indios no quisieron recevir la fe aunque fueron requerido por sus grandes y abominables pecados contra natura" ${ }^{103}$.

51 Matienzo adhiere a las propuestas de Sepúlveda cuando agrega que el territorio comprendido por el virreinato del Perú fue "justamente ganado", aclarando dos elementos importantes: la ausencia de los españoles y la presencia del "abominable pecado contra natura". Con respecto al primero, sabemos que el jurista construyó como 
parámetro de la hombría el modelo de masculinidad hispano-católica, indispensable para el buen gobierno del virreinato. En este caso, la ausencia de los españoles, implicaba que no hubo un control previo en el territorio para evitar la expansión de dicha práctica. Con respecto al segundo, llama la atención que este pecado, en el texto de Matienzo, hace referencia al concubitus masculorum (varón con varón). El jurista deja explícita esta idea, "se ve claro que de estos borrachos vienen a cometer adulterios, e incestos con sus hermanas, hixas y parientas, y aun en algunas partes el pecado nefando, y se matan unos a otros" ${ }^{104}$. Podemos observar que Matienzo se estaba refiriendo a la acción performativa que cometía el varón. Compartimos la reflexión de Serge Gruzinski cuando explica que el pecado nefando no se podía decir (ne-fandus) cuando el acto sexual eran entre dos varones ${ }^{105}$. No es menor mencionar que el " Vocabulario español-latino" (1495) de Elio Antonio de Nebrija, definió a la persona que practicaba la sodomía como "Puto que haze", subrayando la idea que era un varón quien cometía la falta ${ }^{106}$.

Matienzo se sumó a las discusiones teológica-jurídicas que lo ayudaron a construir, discursivamente, a los varones indígenas como practicantes de la sodomía, posicionando a las comunidades andinas en una escala masculina menor, es decir, como representantes de una "masculinidad subordinada" ${ }^{107}$. La definición de un grupo de varones como subordinados es el resultado de la interpretación del grupo de varones que concentra el poder masculino. Lo subordinado siempre será definido como un elemento negativo y ajeno a los códigos y normas señaladas por el poder masculino. Esta idea fue reforzada hacia el siglo XVII, cuando Covarrubias presentó una definición sobre el término varón:

"BARON, que mas propiame[n]te se escriue con v. varon por traer su orige[n] del no[m]bre Latino vir. Algunas vezes distingue el sexo, a diferencia de la he[m]bra, la qual excluye el q[ue] ma[n]da q[ue] suceda en su casa el hijo var[on]. En otra acepcio[n] vale ho[m]bre de juyzio, razo[n] y discurso y de buena co[n]ciencia, como en los casos q[ue] se remite declaracion dellos a juyzio de bue[n] varon" ${ }^{108}$.

La definición de Covarrubias se puede interpretar como una síntesis de los elementos que se discutieron en ambos textos jurídicos. Comprender que el varón debía tener "buen juicio, razón y discurso" implicó construir dos tipos de masculinidades. Por un lado, tenemos al varón español, pero no cualquiera, sino aquel cuyos atributos eran, (a) ser racional (b) pertenecer a la elite y (c) honor y valentía. Como ya ha advertido Pete Sigal, el conquistador español manipuló el poder con un objetivo específico, la prolongación y mantención de las jerarquías de género hispano-católicas ${ }^{109}$.

Estos tres atributos, que definían al varón hispano, presentaban al candidato perfecto para tener el control jurídico y normativizar a los indígenas quienes fueron descritos por el virrey y el jurista como varones cuya masculinidad era opuesta e inferior, es decir, bárbaro, idólatra, polígamo, vicioso y practicantes de la sodomía. La clasificación de estos etnónimos, que permitieron continuar con las estructuras jerárquicas de género -generadas durante la historia española- no sólo abrió el espacio para construir nuevas identidades masculinas subordinadas, sino que dichas identidades se construyeron con el propósito de ser vigiladas y controladas bajo las normativas jurídicas. No sólo hubo una re-estructuración política y económica, sino que, desde el ámbito jurídico, ambos autores abrieron las puertas para reflexionar sobre las modalidades en que se construyeron discursivamente las identidades masculinas españolas e indígenas. 


\section{Reflexiones finales}

55 El abordaje de las obras del virrey Toledo y Matienzo, desde los estudios de masculinidad, tuvo como intencionalidad abrir nuevas reflexiones que no solamente incluyen la importancia de entender las masculinidades como categorías dinámicas que se transforman a lo largo de la historia. La historicidad de dichas categorías envuelve complejidades mayores y están relacionadas con el tipo de soporte y las formas que se desplegaron en los distintos contextos y espacios geográficos.

56 A lo largo de este trabajo, se ha podido detectar que la biografía de ambos autores y el contacto constante que tuvieron con las comunidades andinas -que se logra percibir en las páginas de las Disposiciones Gubernativas y el Gobierno del Perú-, se pueden considerar como fuentes de carácter etnográfico. El ejercicio etnográfico llevado acabo por Toledo y Matienzo es fundamental para relevar la importancia sobre la figura del autor-que en este caso se transformaría en un etnógrafo- y la mirada misma aplicada por él en la construcción discursiva sobre el "otro". Colocar en la palestra de discusión la autoridad del "etnógrafo colonial" como un sujeto que posee una identidad masculina invita a analizar, bajo una dimensión epistemológica vinculada con los estudios de masculinidad, las enunciaciones que están contenidas en un determinado tipo de texto. El carácter jurídico de ambas fuentes revisadas es un ingrediente no menor para legitimar la posición de autoridad masculina ejercida por ambos autores.

Los etnónimos enunciados, en ambos textos jurídicos, no sólo fueron términos que clasificaron a las indígenas, sino que también pueden ser considerados como "tropos de sexualidad" que permiten comprender una manera determinada de explorar cómo se entendía las masculinidades escritas en los Andes coloniales y, específicamente, durante el gobierno de Francisco de Toledo.

El conjunto de normas redactadas por ambos letrados fue el reflejo de la estrategia generada por la Corona castellana para elaborar una división social y construir dos categorías jurídicas que al mismo tiempo generaban dos grupos ontológicamente diferenciados y genéricamente distintos, los varones hispanos e indígenas ${ }^{110}$.

Las lógicas discursivas generadas por estos textos jurídicos permiten comprender que el poder, al estar inmerso en la construcción de dichos discursos, funcionó como una categoría operativa que, en este caso, ayudó a la articulación de las masculinidades tanto hegemónicas como subordinadas. La construcción discursiva de ambos textos está directamente relacionada con los varones que se encontraron en la posición de poder para activar la circulación de los discursos que ellos mismos seleccionaron y utilizaron para legitimar el poder imperial. La instalación de los poderes imperiales y, por lo tanto, de una estructura de género, sustentada sobre el dominio masculino, hispanocatólico, debía ser articulado a través de un aparato jurídico cuyo modelo legal establecía normativas morales que permitieron definir al varón hispano como un sujetos racional, católico y valiente.

60 El análisis de ambas obras jurídicas abre a una problemática mayor y más profunda, ¿qué significó ser un varón dentro de una sociedad colonizada? Esta pregunta no se puede responder sin tener presente el proceso metodológico de la de-construcción de las identidades masculinas que estaban reguladas bajo los marcos legales que permiten y prohíben comportarse de una determinada manera. La forma en que operaron dichas masculinidades estarán sujetas a los mecanismos que harán efectiva la circulación de 
múltiples discursos en torno a cómo debían actuar los varones. Para comprender las masculinidades virreinales se debe tener presente un doble cuestionamiento en el proceso de análisis ¿cómo eran las formas de control de dicho espacio? ¿qué tipo de varones eran los que controlaban todo ese espacio?

\section{Fuentes}

61 Confessionario para los curas de indios, con la instrucion contra sus ritos: y exhortación para ayudar a bien morir y summa de sus privilegios y forma de impedimentos del matrimonio, Antonio Ricardo, Lima, 1585, $240 \mathrm{p}$.

Covarrubias, Sebastián. Tesoro de la lengua castellana, o española por el Licenciado Don Sebastian de Cobarruuias Orozco, Capellan de su Magesta, Maestrescuela y canónigo de la Santa Iglesia de Cuenca, y consultor del Santo Oficio de la Inquisicion. Luis Sanchez, impressor del Rey N. S., Madrid, 1611, 79 p.

Las Casas, Bartolomé, Apologética Historia Sumaria, 2 volúmenes, Universidad Nacional Autónoma de México, Instituto de Investigaciones Históricas, México, 1967 [1559], 779 p.

Matienzo, Juan de, Gobierno del Perú, Institut Francais d'Études andines, Paris-Lima, 1967 [1567], $366 \mathrm{p}$.

65 Nebrija, Elio Antonio de, Vocabulario español-latino, Real Academia Española, Madrid, 1951 [1495], $105 \mathrm{p}$.

66 Santo Tomás, Domingo de, Lexicón o Vocabulario de la lengua general del Perú, Ediciones del Instituto de Historia, Universidad Mayor de San Marcos, Lima, 1951 [1560], 374 p.

67 Sarmiento de Gamboa, Pedro, Historia de los incas, Miraguana ediciones, Madrid, España, 2001 [1571], $191 \mathrm{p}$.

Tercer Cathesisimo y exposición de la doctrina cristiana por sermones, Antonio Ricardo, Lima, $1585,214 \mathrm{p}$.

Toledo, Francisco de, Disposiciones Gubernativas para el Virreinato del Perú, Tomo 1, Escuela de Estudios Hispanoamericanos, Sevilla, 1986, 566 p.

70 Toledo, Francisco de, Disposiciones Gubernativas para el Virreinato del Perú, Tomo 2, Escuela de Estudios Hispanoamericanos, Sevilla, 1989, 539 p.

71 Vargas, Ruben, Los Concilios Limenses (1551-1601), Tomo 1, Talleres gráficos de la Tipografía Peruana, Lima, 1951, 426 p.

72 Vives, Juan Luis, Instrucción de la mujer christiana, Imprenta de Don Benito Cano, Madrid, 1793 [1524], $487 \mathrm{p}$. 


\section{BIBLIOGRAFÍA}

Andrien, Kenneth, “Documentación legal y administrativa”, Pillsbury, Joanne (ed.), Fuentes documentales para los estudios andinos 1530-1900, Vol. I, Pontificia Universidad Católica del Perú, Lima 2016, p. 199-220.

Armas, Fernando, "Religión, género y construcción de una sexualidad en los Andes (siglo XVIXVII). Un acercamiento provisional”, Revistas de Indias, España, vol. LXI, n²23, 2001, p. 673-700.

Bermúdez, Agustín, "El imaginario jurídico de América en el siglo XVI europeo”, en Alemany Bay, Carmen \& Aracil Varón, Beatriz (ed.), América en el imaginario europeo. Estudios sobre la idea de América a lo largo de cinco siglos, Publicaciones Universidad de Alicante, España, 2009, p. 31-56.

Bernard, Carmen \& Gruzinski, Sergei, De la idolatría: una arqueología de las ciencias religiosas, Fondo de Cultura Económica, México, 1992, 226 p.

Brading, David A., Orbe indiano: de la monarquía católica a la república criolla, 1492-1867, Fondo de Cultura Económica, México, 2015, 770 p.

Bleys, Rudi C., The geography of perversion: male-to-male sexual behavior outside the west and the ethnographic imagination, 1750-1918, New York University, New York, 1995, 328 p.

Bourdieu, Pierre, La dominación masculina, Barcelona, Anagrama, 2003, 161 p.

Bullough, Vern L., “On Being a Male in the Middle Ages”, Lees, Clare A., (ed.), Medieval Masculinities: regarding men in the middle ages, University of Minnesota Press, Minneapolis, 1994, p. $31-45$.

Caufield, Sueann, "The history of gender in the historiography of Latin America", The Hispanic American Historical Review, Durham, vol. 81, n³-4, 2001, p. 449-490.

Collier, Richard, Masculinity, law and the family, Routledge, London, 1995, 331 p.

Connell, R. W., Gender \& Power: society, the person and sexual politics, Polity Press, Great Britain, 1987, $352 \mathrm{p}$.

Connell, R. W., Masculinidades, Ediciones Universidad Nacional Autónoma de México, México, 2003,355 p.

David Cook, Noble, “Toledo, Francisco de. Las Ordenanzas (1569-1581)” en Pillsbury, Joanne (ed.), Fuentes documentales para los estudios andinos 1530-1900, vol. III, Pontificia Universidad Católica del Perú, Lima 2016.

Dean, Carolyn, "Andean Androgyny and the making of men" en Klein, Cecilia (ed.), Gender in PreHispanic America, Dumbarton Oaks, Washington, USA, 2001, p. 143-182.

Decoster, Jean-Jacques, “Casas, Bartolomé de las (1474?-1566)”, en Pillsbury, Joanne (ed.), Fuentes documentales para los estudios andinos 1530-1900, vol. II, Pontificia Universidad Católica del Perú, Lima 2016.

Estenssoro, Juan Carlos, Del paganismo a la santidad: La incorporación de los indios del Perú al Catolicismo (1532-1750), Pontificia Universidad católica del Perú, Lima, 2003, 586 p.

Foucault, Michel, Vigilar y castigar: nacimiento de la prisión, Siglo XXI, España, 2000, 314 p.

Foucault, Michel, La verdad y las formas jurídicas, Editorial Gedisa, Barcelona, 2003, 176 p. 
García Ruiz, Pedro Enrique, "La representación del otro. Figuras de la alteridad en la conquista de América. Una propuesta fenomenológica”, Investigaciones Fenomenológicas: Anuario de la Sociedad Española de Fenomenología, n7, 2010, p. 219- 232.

Garza Carvajal, Federico, Butterflies will burn: Prosecuting sodomites in early Modern Spain and Mexico, University of Texas Press, Texas, 2003, 310 p.

Gruzinski, Serge, "The Ashes of desire: homosexuality in Mid-Seventeenth-Century New Spain", Sigal, Pete (ed.), Infamous desire: male homosexuality in colonial Latin America, The University of Chicago Press, Chicago, 2003, p. 197-214.

Hanke, Lewis, El prejuicio racial en el Nuevo Mundo: Aristóteles y los indios de Hispanoamérica, Editorial Universitaria, Santiago, 1958, 155 p.

Hendrix, Scott \& Karant-Nunn, Masculinity in the Reformation Era, Truman State University Press, USA, 2008, $228 \mathrm{p}$.

Horswell, Michael J., Decolonizing the sodomite: queer tropes of sexuality in colonial Andean culture, University of Texas Press, Texas, 2005, 331 p.

Jordan, Mark, The invention of sodomy in Christian theology, The University of Chicago Press, Chicago, United States, 1997, 190 p.

Kimmel, Michael, "La producción teórica sobre la masculinidad: nuevos aportes", Fin de Siglo: Género y cambio civilizatorio, Santiago, 1992, p. 129-140.

Lavrin, Asunsión, Sexuality and marriage in colonial Latin America, University of Nebraska Press, USA, 1989, $349 \mathrm{p}$.

Lepe-Carrión, Patricio, “Civilización y Barbarie. La instauración de la 'diferencia colonial' durante los debates del siglo XVI y su encubrimiento como 'diferencia cultural”, Andamios, vol. 9, n²0, 2012, p. 80-81.

Lugones, María, “Colonialidad y género: hacia un feminismo descolonial”, Mignolo, Walter (comp.), Género y descolonialidad, Del Signo, Buenos Aires, 2014, p. 13-42.

Maestre Sánchez, Alfonso, “'Todas las gentes del mundo son hombres'. El gran debate entre Fray Bartolomé de Las Casas (1474-1566) y Juan Ginés de Sepúlveda (1490-1573)”, Anales del Seminario de Historia de la Filosofía, n²1, 2004, p. 91-134.

Mannarelli, María Emma, Pecados Públicos. La ilegitimidad en Lima, siglo XVII, Centro de la Mujer Peruana, Lima, 1993, 324 p.

Martínez Cereceda, José Luís, Gente de la tierra de guerra. Los lipes en las tradiciones andinas y el imaginario colonial, Pontificia Universidad Católica del Perú y Dirección de Bibliotecas Archivos y Museos de Chile, Lima, 2011, 419 p.

Marzal, Manuel, “Acosta, José de (1540-1600)”, en Pillsbury, Joanne (ed.), Fuentes documentales para los estudios andinos 1530-1900, Vol. II, Pontificia Universidad Católica del Perú, Lima 2016 p. 773-781.

Medina, Rubén, “Masculinidad, imperio y modernidad en Cartas de relación de Hernán Cortés", Hispanic Review, vol. 72, n4, 2004, p. 469-489.

Merluzzi, Manfredi, Gobernando los Andes: Francisco de Toledo virrey del Perú (1569-1581), Fondo editorial de la Pontificia Universidad Católica del Perú, Lima, 2014, 431 p. 
Mignolo, Walter, "Cartas, crónicas y relaciones del descubrimiento y conquista", en Madrigal, Luis Iñigo (coord.), Historia de la literatura hispanoamericana, Tomo 1, Catedra, Madrid, 1982, p. 57-116.

Mignolo, Walter, Historias locales/diseños globales: colonialidad, conocimientos subalternos y pensamiento fronterizo, Ediciones Akal, Madrid, 2011, 452 p.

Mignolo, Walter, “La colonialidad: la cara oculta de la modernidad”, Breitweiser, Sabine (coord.), Modernologías: artistas contemporáneos investigan la modernidad y el modernismo, Museo de Arte Contemporáneo de Barcelona, Barceloona, 2009, p. 39-49.

Mills, Kenneth, Idolatry and its enemies: colonial Andean religion and extirpation, 1640-1750, Princeton University Press, Princeton, New Jersey, 1997, 337 p.

Minello Martini, Nelson, "Masculinidades: un concepto en construcción”, Nueva Antropología, vol. XVIII, $n^{\circ} 61,2002$, p. 11-30.

Molina, Fernanda, “Entre pecado y delito. La administración de la justicia y los límites documentales para el estudio de la sodomía en el Virreinato del Perú (Siglos XVI-XVII)", Revista Allpanchis Phuturinqa, Cuzco, $n^{\circ} 71,2008$, p. 141-186.

Molina, Fernanda, "Los sodomitas Virreinales: entre Sujetos Jurídicos y Especie”, Anuario de Estudios Americanos, Madrid, vol. 67, n¹, 2010, p. 23-52.

Molina, Fernanda, “Más allá de la sodomía. Notas para el estudio de las (homo) sexualidades (pre) modernas en América Latina", Sudamérica: Revista de Ciencias Sociales, Mar del Plata, n¹, 2012, p. 199-219.

Molina, Fernanda, “Femina cum femina. Controversias teológicas, jurídicas y médicas en torno a la sodomía femenina en el mundo hispano (siglos XVI-XVII)”, ARENAL, Granada, vol. 21, n¹, 2014, p. 153-176.

Morong, Germán, "Saberes hegemónicos y proyecto de dominio colonial: los indios en la obra de Juan de Matienzo Gobierno del Perú (1567)”, Fronteras de la Historia, vol. 18, n², 2013, p. 77-103.

Morong, Germán, Saberes hegemónicos y proyecto de dominio colonial. Los indios en la obra Gobierno del Perú de Juan Matienzo (1567), Tesis de doctorado en Estudios Americanos, Universidad de Santiago de Chile, Santiago, 2015, 289 p.

Ojalvo, Alvaro, Masculinidades y poder en la pluma del cronista: masculinidad hegemónica y textos coloniales en los Andes del siglo XVI, Tesis de maestría en Historia mención Etnohistoria, Universidad de Chile, Santiago, Chile, 2011, 133 p.

Pagden, Anthony, La caída del hombre natural: el indio americano y los orígenes de la etnología comparativa, Alianza editorial, Madrid, 1988, 297 p.

Pease, Franklin, “Las crónicas de los Andes en los siglos XVI y XVII”, en Pillsbury, Joanne (ed.), Fuentes documentales para los estudios andinos 1530-1900, Vol. I, Pontificia Universidad Católica del Perú, Lima 2016, p. 45-65.

Pease, Franklin, “Domingo de Santo Tomás (1499-1570)”, en Pillsbury, Joanne (ed.), Fuentes documentales para los estudios andinos 1530-1900, Vol. II, Pontificia Universidad Católica del Perú, Lima 2016, p. 1079-1084.

Pease, Franklin, “Sarmiento de Gamboa, Pedro (1535-1592?), en Pillsbury, Joanne (ed.), Fuentes documentales para los estudios andinos 1530-1900, vol. III, Pontificia Universidad Católica del Perú, Lima 2016, p. 1811-1820. 
Porras Barrenechea, Raúl, Los cronistas del Perú: 1528-1650 y otros ensayos, Banco del Crédito del Perú, Lima, 1986, 964 p.

Presta, Ana María, “Matienzo, Juan de (1520-1579)”, en Pillsbury, Joanne (ed.), Fuentes documentales para los estudios andinos 1530-1900, Vol. III, Pontificia Universidad Católica del Perú, Lima 2016, p. 1417-1424.

Presta, Ana María \& Julien, Catherine, “Polo de Ondegardo (ca. 1520-1575)”, en Pillsbury, Joanne (ed.), Fuentes documentales para los estudios andinos 1530-1900, vol. III, Pontificia Universidad Católica del Perú, Lima, 2016, p. 1635-1646.

Rabasa, José, De la invención de América: La historiografía española y la formación del eurocentrismo, Universidad Iberoamericana, México, 2009, 275 p.

Rivera-Ayala, Sergio, "Barbas, fierros y masculinidad dentro de la mirada colombina", Bulletin of Hispanic Studies, Liverpool, vol. 85, n5, 2010, p. 603-618.

Rose, Sonya O., ¿Qué es historia de género?, Alianza Editorial, Madrid, 2012, 275 p.

Rostworowski, María, La mujer en la época prehispánica, Instituto de Estudios Peruanos, Lima, 1988, p. 1-16.

Said, Edward, Orientalismo, Debolsillo, Barcelona, 2008, 510 p.

Saito, Akira \& Rosas Lauro, Claudia, Reducciones: La concentración forzada de las poblaciones indígenas en el Virreinato del Perú, Lima, Pontificia Universidad Católica del Perú, 2017, 678 p.

Scott, Joan, "El género: una categoría útil para el análisis histórico" en Lamas, Marta (comp.), El género: La construcción cultural de la diferencia sexual, Universidad Nacional Autónoma de México, Programa Universitario de Estudio de Género, México, 2015, 367 p.

Sigal, Pete, Infamous Desire: male homosexuality in colonial Latin America, The University of Chicago Press, Chicago, 2003.

Sigal, Pete, “(Homo) Sexual Desire and Masculine Power in Colonial Latin America: Notes toward an Integrated Analysis", Sigal, Pete (editor), Infamous desire: male homosexuality in colonial Latin America, The University of Chicago Press, Chicago, 2003, p. 1-24.

Sigal, Pete, The flower and the scorpion: sexuality and ritual in early nahua culture, Duke University Press, Durham, 2011, 362 p.

Silverblatt, Irene, "Principios de organización femenina en el Tahuantinsuyu", Revista del Museo Nacional, nXLII, 1976, p. 299-340.

Silverblatt, Irene, Luna, sol y brujas: géneros y clases en los Andes prehispánicos y coloniales, Centro de estudios regionales Bartolomé de las Casas, Perú, 1990, 201 p.

Sinha, Mrinalini, "Giving masculinity a history: Some contributions from the Historiography of Colonial India", Gender \& History, London, vol. 11, n³, 1999, p. 445-460.

Solodkow, David M., Etnógrafos coloniales: escritura, alteridad y eurocentrismo en la conquista de América, Tesis de doctorado en Español y Portugués, Vanderbilt University, Nashville, Tennesee, $2009,554 \mathrm{p}$.

Tau Anzoátegui, Víctor, El jurista en el Nuevo Mundo, Pensamiento. Doctrina. Mentalidad, Max Planck Institute for European Legal History, Frankfurt am Main, 2016, 267 p.

Tejero, Eloy, "De la visión del matrimonio desde la revelación a su inserción en el derecho natural" en Arellano, Ignacio \& Usunáriz, Jesús María (coord.), El matrimonio en Europa y el mundo hispánico siglo XVI y XVII, Ediciones Visor, Madrid, 2005, p. 113-128. 
Timberlake, Marie, “Concilios provinciales de Lima. Textos e imágenes” en Pillsbury, Joanne (ed.), Fuentes documentales para los estudios andinos 1530-1900, vol. I, Pontificia Universidad Católica del Perú, Lima 2016.

Trexler, Richard, Sex and conquest: gendered violence, political order, and the European Conquest of the Americas, Polity Press, Cambridge, 1995, 292 p.

Twinam, Ann, Vidas Publicas, secretos privados: Género, honor, sexualidad e ilegitimidad en la Hispanoamérica colonial, Fondo de Cultura Económica, México, 2009, 500 p.

Wachtel, Nathan, Los vencidos: Los indios del Perú frente a la conquista española (1530-1570), Alianza Editorial, Madrid, 1976, $413 \mathrm{p}$.

Weisner-Hanks, Merry, Cristianismo y sexualidad en la edad moderna, Ediciones Siglo XXI, Madrid, 2001, 327 p.

Yarrow, Simon, "Masculinity as a World Historical Category of Analysis" en Arnold, John and Bardy, Sean (ed.), What is Masculinity?: Historical Dynamics from Antiquity to the Contemporary World, palgrave macmillian, London, 2013, p. 114-138.

\section{NOTAS}

1. Brading, David A., Orbe indiano: de la monarquía católica a la república criolla, 1492-1867, Fondo de Cultura Económica, México, 2015, p. 12.

2. Pagden, Anthony, La caída del hombre natural: el indio americano y los orígenes de la etnología comparativa, Alianza editorial, Madrid, 1988, p. 164.

3. Mignolo, Walter, Historias locales/diseños globales: Colonialidad, conocimientos subalternos y pensamiento fronterizo, Ediciones Akal, Madrid, 2011, p. 49, 76 y 77.

4. Lugones, María, “Colonialidad y género: hacia un feminismo descolonial”, Mignolo, Walter (compilador), Género y descolonialidad, Del Signo, Buenos Aires, 2014, p. 13-23.

5. Recomendamos el trabajo del sociólogo Michael Kimmel quien subraya la importancia de la historia como un factor importante en la construcción de las masculinidades. Kimmel, Michael, "La producción teórica sobre la masculinidad: nuevos aportes", Fin de Siglo: Género y cambio civilizatorio, Santiago, 1992, p. 135. Para el caso de la reflexión de las masculinidades como una "categoría", recomendamos el clásico trabajo de Scott, Joan, "El género: una categoría útil para el análisis histórico" en Lamas, Marta (comp.), El género: La construcción cultural de la diferencia sexual, Universidad Nacional Autónoma de México, Programa Universitario de Estudio de Género, México, 2015, p. 265-302 y Yarrow, Simon, "Masculinity as a World Historical Category of Analysis" en Arnold, John and Bardy, Sean (ed.), What is Masculinity?: Historical Dynamics from Antiquity to the Contemporary World, palgrave macmillian, London, 2013, p. 114-138.

6. Con respecto a los trabajos elaborados en la década de los ochenta y noventa, ver Silverblatt, Irene, "Principios de organización femenina en el Tahuantinsuyu", Revista del Museo Nacional, vol. XLII, 1976; Silverblatt, Irene, Luna, sol y brujas: géneros y clases en los Andes prehispánicos y coloniales, Centro de estudios regionales 'Bartolomé de las casas', Perú, 1990; Rostworowski, María, La mujer en la época prehispánica, Instituto de Estudios Peruanos, Lima, 1988; Lavrin, Asunsión, Sexuality and marriage in colonial Latin America, University of Nebraska Press, USA, 1989 y Mannarelli, María Emma, Pecados Públicos. La ilegitimidad en Lima, siglo XVII, Centro de la Mujer Peruana, Perú, 1993.

7. Para una discusión más general ver Caufield, Sueann, "The history of gender in the historiography of Latin America", The Hispanic American Historical Review, Durham, vol. 81, n³-4, 2001, p. 449-490. 
8. Para un estudio de las masculinidades debemos recomendar el monumental trabajo de Connell, R.W., Masculinidades, Ediciones Universidad Nacional Autónoma de México, México, 2003. Para una mayor comprensión sobre las masculinidades en la historia, ver Rose, Sonya O., ¿Qué es historia de género?, Alianza Editorial, Madrid, 2012. Para el lector que desea comprender las corrientes teóricas que nutrieron a los estudios de masculinidad, ver Minello Martini, Nelson, "Masculinidades: un concepto en construcción", Nueva Antropología, vol. XVIII, n61, 2002, p. 11-30.

9. Trexler, Richard, Sex and conquest: gendered violence, political order, and the European Conquest of the Americas, Polity Press, Cambridge, 1995; Sigal, Pete, The flower and the scorpion: sexuality and ritual in early nahua culture, Duke University Press, Durham, 2011 y Horswell, Michael J., Decolonizing the sodomite: queer tropes of sexuality in colonial Andean culture, University of Texas Press, USA, 2005.

10. Para el caso del chamán varón (tercer género) a nivel americano, ver Trexler, R., Sex and conquest, Op.Cit. Para el caso mesoamericano ver los trabajos de Sigal, Pete, Infamous Desire: male homosexuality in colonial Latin America, The University of Chicago Press, Chicago, 2003; Sigal, P., The flower and the scorpion, Op.Cit; Medina, Rubén, "Masculinidad, imperio y modernidad en Cartas de relación de Hernán Cortés", Hispanic Review, vol. 72, n4, 2004, p. 469-489. Para el caso andino, ver Horswell, M., Decolonizing the sodomite, Op.Cit. Sobre las primeras nociones de las masculinidades en la historia de América, ver Rivera-Ayala, Sergio, "Barbas, fierros y masculinidad dentro de la mirada colombina", Bulletin of Hispanic Studies, vol.85, n5, 2010, p. 603-618. Finalmente para la relación entre masculinidades y honor, ver Twinam, Ann, Vidas Publicas, secretos privados: Género, honor, sexualidad e ilegitimidad en la Hispanoamérica colonial, Fondo de Cultura Económica, México, 2009.

11. Mignolo, Walter, "Cartas, crónicas y relaciones del descubrimiento y conquista", en Madrigal, Luis Iñigo (coordinador), Historia de la literatura hispanoamericana, Tomo 1, Catedra, Madrid, 1982, p. 57-116.

12. Este concepto fue creado por José Luis Martínez C., en el marco de sus proyectos de investigación Fondecyt en torno al mundo andino colonial, titulados, Discursos andinos coloniales. Soportes, confluencias y transformaciones $\left(\mathrm{n}^{\circ} 1090110\right)$ y Sistemas andinos de registro y de comunicación y semiosis andina colonial ( $\left.\mathrm{n}^{\circ} 1130431\right)$ durante los años 2009 y 2014.

13. Sigal, P., The flower and the scorpion, Op. Cit., p. 26.

14. Garza Carvajal, Federico, Butterflies will burn: Prosecuting sodomites in early Modern Spain and Mexico, University of Texas Press, Texas, United States, 2003, p. 39.

15. O'Gorman, Edmundo, La invención de América, Fondo de Cultura Económica, México, 1991, p. 60.

16. Bourdieu, Pierre, La dominación masculina, Barcelona, Anagrama, 2003, p. 49.

17. Estenssoro, Juan Carlos, Del paganismo a la santidad: la incorporación de los indios del Perú al catolicismo 1532-1750, Lima, Pontificia Universidad Católica del Perú, 2003, p. 140.

18. Horswell, M., Decolonizing the sodomites, Op. Cit.

19. Rabasa, José, De la invención de América: La historiografía española y la formación del eurocentrismo, Universidad Iberoamericana, México, 2009, p. 29.

20. Rose, S. ¿Qué es historia de género?, Op. Cit., p. 121.

21. Presta, Ana María, "Matienzo, Juan de (1520-1579)", en Pillsbury, Joanne (editor), Fuentes documentales para los estudios andinos 1530-1900, Vol. III, Pontificia Universidad Católica del Perú, Lima, 2016, p. 1417. Ver también el capítulo 3, "El Gobierno del Perú de Juan de Matienzo. En la senda del humanismo jurídico" en Tau Anzoátegui, Víctor, El jurista en el Nuevo Mundo, Pensamiento. Doctrina. Mentalidad, Max Planck Institute for European Legal History, Frankfurt am Main, 2016, p. 35-69.

22. Estenssoro, J., Del paganismo a la santidad, Op. Cit, 140. 
23. Merluzzi, Manfredi, Gobernando los Andes: Francisco de Toledo virrey del Perú (1569-1581), Fondo editorial de la Pontificia Universidad Católica del Perú, Lima, 2014, p. 21.

24. Presta, A., “Matienzo, Juan de”, en Pillsbury, J., Fuentes documentales, vol.III, Op. Cit. p. 1421.

25. David Cook, Noble, "Toledo, Francisco de. Las Ordenanzas (1569-1581)" en Pillsbury, J., Fuentes documentales, Vol. III, Op. Cit, p. 1858-1859.

26. Mignolo, Walter, "La colonialidad: la cara oculta de la modernidad", Breitweiser, Sabine (coord.), Modernologías: artistas contemporáneos investigan la modernidad y el modernismo, Museo de Arte Contemporáneo de Barcelona, Barcelona, 2009, p. 39-49.

27. Solodkow, David M., Etnógrafos coloniales: escritura, alteridad y eurocentrismo en la conquista de América, Tesis de doctorado en Español y Portugués, Vanderbilt University, Nashville, Tennesee, 2009.

28. Foucault, Michel, Vigilar y castigar: nacimiento de la prisión, Siglo XXI, España, 2000.

29. Saito, Akira \& Rosas Lauro, Claudia, Reducciones: La concentración forzada de las poblaciones indígenas en el Virreinato del Perú, Lima, Pontificia Universidad Católica del Perú, 2017.

30. Pease, Franklin, "Las crónicas de los Andes en los siglos XVI y XVII" en Pillsbury, Joanne (ed.), Fuentes documentales para los estudios andinos 1530-1900, vol. I, Pontificia Universidad Católica del Perú, Lima 2016, p. 51.

31. Estenssoro, J., Del paganismo a la santidad, Op. Cit., p. 243.

32. Merluzzi, Manfredi, Gobernando los Andes, Op. Cit., p. 44-51.

33. La idea de continuar con las estructuras andinas ya fue desarrollada en la clásica obra, Wachtel, Nathan, Los vencidos: Los indios del Perú frente a la conquista española (1530-1570), Alianza Editorial, Madrid, 1976.

34. Para el caso de Domingo de Santo Tomás ver Santo Tomás, Domingo de, Lexicón o Vocabulario de la lengua general del Perú, Ediciones del Instituto de Historia, Universidad Mayor de San Marcos, Lima, 1951 [1560] y para Bartolomé de Las Casas ver Las Casas, Bartolomé, Apologética Historia Sumaria, Universidad Nacional Autónoma de México, Instituto de Investigaciones Históricas, México, 1967 [1559].

35. Timberlake, Marie, “Concilios provinciales de Lima. Textos e imágenes" en Pillsbury J. Fuentes documentales, vol. I, Op. Cit, p. 353-354.

36. Pease, Franklin, "Domingo de Santo Tomás (1499-1570)" en Pillsbury, J. (ed.), Fuentes documentales para los estudios andinos 1530-1900, Vol. II, Pontificia Universidad Católica del Perú, Lima 2016, p. 1080-1081.

37. Decoster, Jean-Jacques, "Casas, Bartolomé de las (1474?-1566)" en Pillsbury, J., Fuentes documentales, Vol. II, Op.Cit, p. 969-971.

38. Marzal, Manuel, “Acosta, José de (1540-1600)” en Pillsbury, J., Fuentes documentales, vol. II, Op. Cit., p. 773-781.

39. Merluzzi, Manfredi, Gobernando los Andes, Op. Cit., p. 123-124.

40. Presta, Ana María \& Julien, Catherine, "Polo de Ondegardo (ca. 1520-1575)" en Pillsbury, J., Fuentes Documentales, vol. III, Op. Cit., p. 1635-1646.

41. Pease, Franklin, "Sarmiento de Gamboa, Pedro (1535-1592?) en Pillsbury, J, Fuentes Documentales, vol. III, Op. Cit., p. 1811-1813.

42. Morong, Germán, "Saberes hegemónicos y proyecto de dominio colonial: los indios en la obra de Juan de Matienzo Gobierno del Perú (1567)”, Fronteras de la Historia, vol. 18, n², 2013, p. 83.

43. Pagden, A., La caída del hombre, Op. Cit., p. 116-153.

44. Maestre Sánchez, Alfonso, “' 'Todas las gentes del mundo son hombres'. El gran debate entre Fray Bartolomé de Las Casas (1474-1566) y Juan Ginés de Sepúlveda (1490-1573)”, Anales del Seminario de Historia de la Filosofía, n²1, 2004, p. 101-104.

45. Maestre Sánchez, A., “'Todas las gentes' ”, Op. Cit., p. 105.

46. Brading, D., Orbe indiano, Op. Cit., p. 106.

47. Maestre Sanchez, A., “'Todas las gentes' ”, Op. Cit., p. 118-120. 
48. Brading, D., Orbe indiano, Op. Cit., p. 160.

49. Lepe-Carrión, Patricio, "Civilización y Barbarie. La instauración de la 'diferencia colonial' durante los debates del siglo XVI y su encubrimiento como 'diferencia cultural' ", Andamios, vol. $9, \mathrm{n}^{\circ} 20,2012$, p. 80-81.

50. Morong, German, Saberes hegemónicos y proyecto de dominio colonial. Los indios en el obra Gobierno del Perú de Juan Matienzo (1567), Tesis de doctorado en Estudios Americanos, Universidad de Santiago de Chile, Santiago, 2015.

51. Porras Barrenechea, Raúl, Los cronistas del Perú: 1528-1650 y otros ensayos, Banco del Crédito del Perú, Lima, 1986, p. 39.

52. Solodkow, D., Etnógrafos coloniales, Op. Cit., p. 6-8.

53. Horswell M., Descolonizing the sodomite, Op. Cit., p. 12.

54. Collier, Richard, Masculinity, law and the family, Routledge, London, 1995, p. 73.

55. Bermúdez, Agustín, "El imaginario jurídico de América en el siglo XVI europeo" en Alemany Bay, Carmen \& Aracil Varón, Beatriz (ed.), América en el imaginario europeo. Estudios sobre la idea de América a lo largo de cinco siglos, Publicaciones Universidad de Alicante, España, 2009, p. 32.

56. Andrien, Kenneth, "Documentación legal y administrativa" en Pillsbury, J. (ed.), Fuentes documentales, vol. I, Op. Cit., p. 201.

57. Solodkow, D., Etnógrafos Coloniales, Op. Cit., p. 24.

58. Weisner-Hanks, Merry, Cristianismo y sexualidad en la edad moderna, Ediciones Siglo XXI, Madrid, 2001.

59. Una síntesis de este concepto, se puede ver en la nota al pie $n^{\circ} 36$ de la investigación doctoral de Germán Morong. Ver Morong, G., Saberes hegemónicos, Op. Cit., p. 30.

60. García Ruiz, Pedro Enrique, "La representación del otro. Figuras de la alteridad en la conquista de América. Una propuesta fenomenológica”, Investigaciones Fenomenológicas: Anuario de la Sociedad Española de Fenomenología, n7, 2010, p. 227.

61. Bernard, Carmen \& Gruzinski, Sergei, De la idolatría: una arqueología de las ciencias religiosas, Fondo de Cultura Económica, México, 1992, p. 45.

62. Mills, Kenneth, Idolatry and its enemies: colonial Andean religion and extirpation, 1640-1750, Princeton University Press, Princeton, New Jersey, 1997, p. 197.

63. Hendrix, Scott \& Karant-Nunn, Masculinity in the Reformation Era, Truman State University Press, USA, 2008.

64. Foucault, Michel, La verdad y las formas jurídicas, Editorial Gedisa, Barcelona, 2003, p. 123.

65. Covarrubias, Sebastián. Tesoro de la lengua castellana, o española compuesto por el Licenciado Don Sebastian de Cobarruuias Orozco, Capellan de su Magesta, Maestrescuela y canónigo de la Santa Iglesia de Cuenca, y consultor del Santo Oficio de la Inquisicion. Luis Sanchez, impressor del Rey N. S., Madrid, 1611, p. 591v.

66. Matienzo, Juan de, Gobierno del Perú, Institut Francais d' Études andines, Paris-Lima, 1967, p. 340. Entre sus ordenanzas, Toledo estableció que "los naturales se reduzcan y congreguen a pueblos". Toledo, Francisco de, Disposiciones Gubernativas para el Virreinato del Perú, Tomo 2, Escuela de Estudios Hispanoamericanos, Sevilla, España, 1989, p. 47.

67. Foucault, M., La verdad y las formas, Op. Cit., p. 105.

68. Matienzo, J. Op. Cit., p. 48. En esta misma obra, el autor enuncia varias veces este término. Ver. Matienzo, J., Gobierno del Perú, Op. Cit., p. 51 y 60.

69. Connell, R. W., Gender \& Power: society, the person and sexual politics, Polity Press, Great Britain, 1987, p. 250 y Weiner-Hanks, M, Cristianismo y sexualidad, Op. Cit.

70. Matienzo, J., Gobierno del Perú, Op. Cit., p. 196. Como se puede apreciar en el trabajo doctoral de Germán Morong la idea del "varón noble" ya estaba presente en la obra Dialogus relatoris et advocati Pinciani senatus (1558) de Matienzo. Morong, G., Saberes hegemónicos, Op. Cit., p. 120.

71. Ver el segundo capítulo de la tesis doctoral de Martínez, titulado "Hablar y escribir en el siglo XVI" en Martínez Cereceda, José Luís, Gente de la tierra de guerra. Los lipes en las tradiciones andinas y 
el imaginario colonial, Pontificia Universidad Católica del Perú y Dirección de Bibliotecas Archivos y Museos de Chile, Lima, 2011, p. 59.

72. Covarrubias, Sebastián. Tesoro de la lengua castellana, o española compuesto por el Licenciado Don Sebastian de Cobarruuias Orozco, Capellan de su Magesta, Maestrescuela y canónigo de la Santa Iglesia de Cuenca, y consultor del Santo Oficio de la Inquisicion, Luis Sanchez, impressor del Rey N. S., Madrid, 1611, p. 319, 477 y 564.

73. Ver nota al pie en Connell, R. W., Masculinidades, Universidad Nacional Autónoma de México, México, 2003, p. 55.

74. Connell, R. W., Masculinidades, Op. Cit, p. 116-117.

75. Toledo, F., Disposiciones Gubernativas, Tomo 2, Op. Cit., p. 297.

76. Merluzzi, M., Gobernando los Andes, Op. Cit., p. 280.

77. Toledo, Francisco de, Disposiciones Gubernativas para el Virreinato del Perú, Tomo 1, Escuela de Estudios Hispanoamericanos, Sevilla, 1986, p. 33.

78. Bullough, Vern L., "On Being a Male in the Middle Ages", Lees, Clare A., (ed.), Medieval Masculinities: regarding men in the middle ages, University of Minnesota Press, Minneapolis, 1994, p. 31-45. Michael Horswell dedica un capítulo en su obra, donde también hace mención sobre esta tradición, centrándose en las epopeyas, romances y el poema del Mío Cid. Horswell, M., Decoloninzing the sodomite, Op. Cit., p. 29-67.

79. Toledo, F., Disposiciones Gubernativas, tomo 1, Op. Cit., p. 486.

80. Ojalvo, Alvaro, Masculinidades y poder en la pluma del cronista: masculinidad hegemónica y textos coloniales en los Andes del siglo XVI, Tesis de maestría en Historia mención Etnohistoria, Universidad de Chile, Santiago, Chile, 2011.

81. Vargas, Rubén, Los Concilios Limenses (1551-1601), Tomo 1, Talleres gráficos de la Tipografía Peruana, Lima, 1951, p. 16-17.

82. Tejero, Eloy, "De la visión del matrimonio desde la revelación a su inserción en el derecho natural”, en Arellano, Ignacio \& Usunáriz, Jesús María (coord.), El matrimonio en Europa y el mundo hispánico siglo XVI y XVII, Ediciones Visor, Madrid, 2005, p. 113-116.

83. Toledo, F., Disposiciones Gubernativas, Tomo 2, Op. Cit., p. 213.

84. Weisner-Hanks, M., Cristianismo y sexualidad, Op.Cit, p. 175.

85. Vives, Juan Luis, Instrucción de la mujer christiana, Imprenta de Don Benito Cano, Madrid, 1793 [1524], p. 271-271.

86. Dean, Carolyn, “Andean Androgyny and the making of men”, en Klein, Cecilia (ed.), Gender in Pre-Hispanic America, Dumbarton Oaks, Washington, USA, 2001.

87. Armas, Fernando, "Religión, género y construcción de una sexualidad en los Andes (siglo XVIXVII). Un acercamiento provisional”, Revistas de Indias, España, LXI, 223, 2001, p. 691-692.

88. Matienzo, J., Gobierno del Perú, Op. Cit., p. 18.

89. Posterior a las discusiones generadas en el tercer concilio limense, se puede detectar tanto en el Tercero Cathesismo (1585) como en el Confesionario para curas (1585) la construcción de dos identidades diametralmente opuestas, los españoles como cristianos-viracochas o señores y los indígenas como idolatras-siervos. Para el caso de la primera obra, ver Tercer Cathesisimo y exposición de la doctrina cristiana por sermones, Antonio Ricardo, Lima, 1585, p. 144 y 205r. Para el caso de la segunda, ver Confessionario para los curas de indios, con la instrucion contra sus ritos: $y$ exhortación para ayudar a bien morir y summa de sus privilegios y forma de impedimentos del matrimonio, Antonio Ricardo, Lima, 1585, p. 24r-25.

90. Pagden, A., La caída del hombre, Op. Cit., p. 239.

91. Si bien Toledo no menciona este término fue Pedro Sarmiento de Gamboa, cronista del virrey, quien discutió esta palabra, utilizando diferentes sinónimos como "pecado nefando", "pecado contra natura". Ver Sarmiento de Gamboa, Pedro, Historia de los incas, Miraguana ediciones, Madrid, España, 2001 [1571], p. 24, 50 y 51. 
92. Molina, Fernanda, "Los sodomitas Virreinales: entre Sujetos Jurídicos y Especie”, Anuario de Estudios Americanos, Madrid, vol. 67, $\mathrm{n}^{\circ} 1,2010$, p. 25. Esta lista de pecados ya fue trabajada en Garza Carvajal, F., Butterflies will burn, Op. Cit., p. 50.

93. Véase también Molina, Fernanda, "Más allá de la sodomía. Notas para el estudio de las (homo) sexualidades (pre) modernas en América Latina", Sudamérica: Revista de Ciencias Sociales, Mar del Plata, $\mathrm{n}^{\circ} 1,2012$, p. 210.

94. Jordan, Mark, The invention of sodomy in Christian theology, The University of Chicago Press, Chicago, United States, 1997, p. 26.

95. Con respecto a la relación sexual entre mujeres (femina cum femina), recomendamos el trabajo de Molina, Fernanda, "Femina cum femina. Controversias teológicas, jurídicas y médicas en torno a la sodomía femenina en el mundo hispano (siglos XVI-XVII)", ARENAL, Granada, vol. 21, n¹, 2014, p. 153-176.

96. Jordan, M., The invention of sodomy, Op. Cit., p. 146-147.

97. Molina, Fernanda, "Entre pecado y delito. La administración de la justicia y los límites documentales para el estudio de la sodomía en el Virreinato del Perú (Siglos XVI-XVII)", Revista Allpanchis Phuturinqa, Cuzco, $\mathrm{n}^{\circ} 71,2008$, p. 142.

98. Matienzo, J., Gobierno del Perú, Op. Cit., p. 250.

99. Covarrubias, S., Tesoro de la lengua, Op. Cit, p. 355.

100. Morong, G., Saberes hegemónicos, Op. Cit., p. 225.

101. Bleys, Rudi C., The geography of perversion: male-to-male sexual behavior outside the west and the ethnographic imagination, 1750-1918, New York University, New York, 1995, p. 27.

102. Covarrubias, S., Tesoro de la lengua, Op. Cit., p. 5-6.

103. Matienzo, J., Gobierno del Perú, Op. Cit., p. 11. El destacado es nuestro.

104. Matienzo, J., Gobierno del Perú, Op. Cit, p. 80. El destacado es nuestro.

105. Gruzinski, Serge, "The Ashes of desire: homosexuality in Mid-Seventeenth-Century New Spain", Sigal, Pete (ed.), Infamous desire: male homosexuality in colonial Latin America, The University of Chicago Press, Chicago, 2003, p. 200.

106. Nebrija, Elio Antonio de, Vocabulario español-latino, Real Academia Española, Madrid, 1951 [1495], p. XCVr.

107. Connell, R. W., Masculinidades, Op. Cit., p. 118-119.

108. Covarrubias, S., Tesoro de la lengua, Op. Cit., p. 122.

109. Sigal, Pete, “(Homo) Sexual Desire and Masculine Power in Colonial Latin America: Notes toward an Integrated Analysis", Sigal, P., Infamous Desire, Op. Cit., p. 10.

110. Esta ida ya ha sido explorada por Edward Said desde los estudios culturales, ver Said, Edward, Orientalismo, Debolsillo, Barcelona, 2008 y desde los estudios de masculinidad por Richard Trexler para el caso de América y su relación con el imperio espalño, ver Trexler, R., Sex and Conquest, Op.Cit. y Mrilanini Sinha para el caso de la India y su conexión con el imperio británcio, ver Sinha, Mrinalini, "Giving masculinity a history: Some contributions from the Historiography of Colonial India”, Gender \& History, London, vol. 11, n³, 1999, p. 445-460.

\section{RESÚMENES}

Durante el gobierno del virrey Francisco de Toledo (1569-1581) se generaron textos jurídicos que tuvieron un impacto discursivo en la articulación de las identidades masculinas -tanto hispanas 
como indígenas-, generando una jerarquía entre masculinidades a partir de una serie de variables, como la religión y el status. Para discutir esta hipótesis abordaremos las "Ordenanzas" del propio virrey Toledo (1575-1580) así como el “Gobierno del Perú” de Juan de Matienzo (1567). Esta última tuvo una influencia importante en las políticas y ordenanzas toledanas. Ambos corpus jurídicos se analizarán a la luz de los aportes teóricos de los estudios de masculinidad, los cuales permiten indagar en las construcciones de identidades y en las representaciones de género como procesos sociales e históricamente determinados.

During Francisco de Toledo's Viceroyalty (1569-1581), legal texts had a discursive impact in the articulation of Spanish and indigenous male identities: these legal statuses established a hierarchy of masculinity through different variables such as religion and social status, among others. This study discusses this hypothesis through the analysis of two legal texts: Viceroy Toledo's “Ordenanzas” (1575-1580) and jurist Juan de Matienzo's “Gobierno del Perú” (1567), which influenced Toledo's politics. In doing so, the article aims to understand, through a theoretical approach based on the field of masculinity studies, the constructions of gender identities as a social and historical process.

Durant le gouvernement du vice-roi Francisco de Toledo (1569-1581), les textes légaux avait un impact discursif sur l'articulation des identités masculines -aussi bien espagnoles qu'indigènesdonnant lieu à une hiérarchie entres masculinités à partir d'une série de variables, comme la religion et le statut. Pour débattre de cette hypothèse, nous nous pencherons sur les "Ordenanzas" du vice-roi Toledo (1575-1580), ainsi que sur le "Gobierno del Perú" de Juan de Matienzo (1567), qui eut une influence importance sur la politique de Toledo. S'inscrivant dans le champ des études de la masculinité, l'analyse de ce corpus proposée dans cet article vise à comprendre les constructions des identités de genre en tant que processus historique et social.

\section{ÍNDICE}

Mots-clés: études de la masculinité, identités masculines, textes légaux, Francisco de Toledo, Juan de Matienzo, vice-royaume du Pérou

Palabras claves: Estudios de masculinidad, identidades masculinas, textos jurídicos, virrey Francisco de Toledo, Juan de Matienzo, virreinato del Perú

Keywords: Masculinity Studies, male identities, legal texts, Viceroy Francisco de Toledo, Juan de Matienzo, Viceroyalty of Peru

\section{AUTOR}

\section{ALVARO OJALVO PRESSAC}

Magister en Historia mención Etnohistoria, Universidad de Chile. Estudiante del programa de doctorado de la Universidad de Buenos Aires, con mención en Historia. Investigador Asociado en el Centro de Estudios Históricos, Universidad Bernardo O'Higgins. Santiago, Chile.

alvaroaojalvo[at]gmail.com 